\title{
India-Asia collision and the Cenozoic slowdown of the Indian plate: Implications for the forces driving plate motions
}

\author{
Alex Copley, ${ }^{1}$ Jean-Philippe Avouac, ${ }^{1}$ and Jean-Yves Royer ${ }^{2}$ \\ Received 21 May 2009; revised 12 August 2009; accepted 25 September 2009; published 17 March 2010.
}

[1] The plate motion of India changed dramatically between 50 and $35 \mathrm{Ma}$, with the rate of convergence between India and Asia dropping from $\sim 15$ to $\sim 4 \mathrm{~cm} / \mathrm{yr}$. This change is coincident with the onset of the India-Asia collision, and with a rearrangement of plate boundaries in the Indian Ocean. On the basis of a simple model for the forces exerted upon the edges of the plate and the tractions on the base of the plate, we perform force balance calculations for the precollision and postcollision configurations. We show that the observed Euler poles for the Indian plate are well explained in terms of their locations and magnitudes if (1) the resistive force induced by mountain building in the Himalaya-Tibet area is $\sim 5-6 \times 10^{12} \mathrm{~N} / \mathrm{m},(2)$ the net force exerted upon the Indian plate by subduction zones is similar in magnitude to the ridge-push force $\left(\sim 2.5 \times 10^{12} \mathrm{~N} / \mathrm{m}\right)$, and (3) basal tractions exert a resisting force that is linearly proportional to the plate velocity in the hot spot reference frame. The third point implies an asthenospheric viscosity of $\sim 2-5 \times 10^{19} \mathrm{~Pa} \mathrm{~s}$, assuming a thickness of $100-150 \mathrm{~km}$. Synthetic Euler poles show that crustal thickening in the Tibetan Plateau was the dominant cause of the Cenozoic slowdown of the Indian plate.

Citation: Copley, A., J.-P. Avouac, and J.-Y. Royer (2010), India-Asia collision and the Cenozoic slowdown of the Indian plate: Implications for the forces driving plate motions, J. Geophys. Res., 115, B03410, doi:10.1029/2009JB006634.

\section{Introduction}

[2] Plate reconstructions [e.g., Patriat and Achache, 1984; Royer and Patriat, 2002] show that the convergence velocity between India and Asia, and the position of the Euler pole that describes the relative motion, changed dramatically at $\sim 50-35 \mathrm{Ma}$ (Figure 1). The rate of convergence started decreasing at about the time of the initial contact of the Indian and Asian continental margins and the cessation of marine sedimentation in the western Himalayas [e.g., Guillot et al., 2003; Rowley, 1996]. The relative velocity continued to decrease as the Himalayan orogen developed and the Tibetan Plateau was uplifted. Rowley and Currie [2006] suggest the Tibetan Plateau had attained close to its current elevation at $\sim 35 \mathrm{Ma}$, after which the Indian plate motion stabilized. The plate boundaries in the Indian Ocean were becoming rearranged at around the same time [e.g., Liu et al., 1983] (Figure 1). Despite the uncertainties involved in dating past tectonics events, it seems clear that the reorganization of the Indian plate boundaries and the dramatic slowdown of India relative to Asia occurred at around the time of continent-continent collision in Tibet, suggesting some causal relationship [e.g., Molnar and

\footnotetext{
${ }^{1}$ Tectonics Observatory, Division of Geological and Planetary Sciences, California Institute of Technology, Pasadena, California, USA.

${ }^{2}$ Domaines Oceaniques, IUEM, UBO, CNRS, Plouzane, France.

Copyright 2010 by the American Geophysical Union. 0148-0227/10/2009JB006634
}

Tapponnier, 1975; Patriat and Achache, 1984]. In this paper we further investigate this possibility, based on an analysis of the forces applied to the Indian plate, and how they have changed with time as the collision developed.

[3] We will first present an updated model of the kinematics of the Indian plate, and discuss how this model compares with the chronology of mountain building in Asia. We next describe the forces acting upon the boundaries and base of the Indian plate. By requiring the net force on the plate to be zero (because plates must be in quasi-static equilibrium), we are able to estimate the magnitudes of the plate boundary forces and basal tractions. We then use the estimated basal tractions to infer the mechanical properties of the asthenosphere. Finally, we discuss the causes of the Cenozoic slowdown of the Indian plate, and the implications of our study for the wider debate on the forces driving plate tectonics.

\section{Motion of the Indian Plate and Tectonic Evolution of the India-Asia Collision}

[4] The motion of India relative to stable Eurasia can be reconstructed from the history of spreading in the Indian and Atlantic oceans and the rifting in east Africa [e.g., Patriat and Achache 1984]. Various reconstructions have been proposed, and for the purposes of this study we have updated the previous models based on the most recent analysis of magnetic anomalies in the Indian and Atlantic oceans (Figure 2). We used the rotations of DeMets et al. 

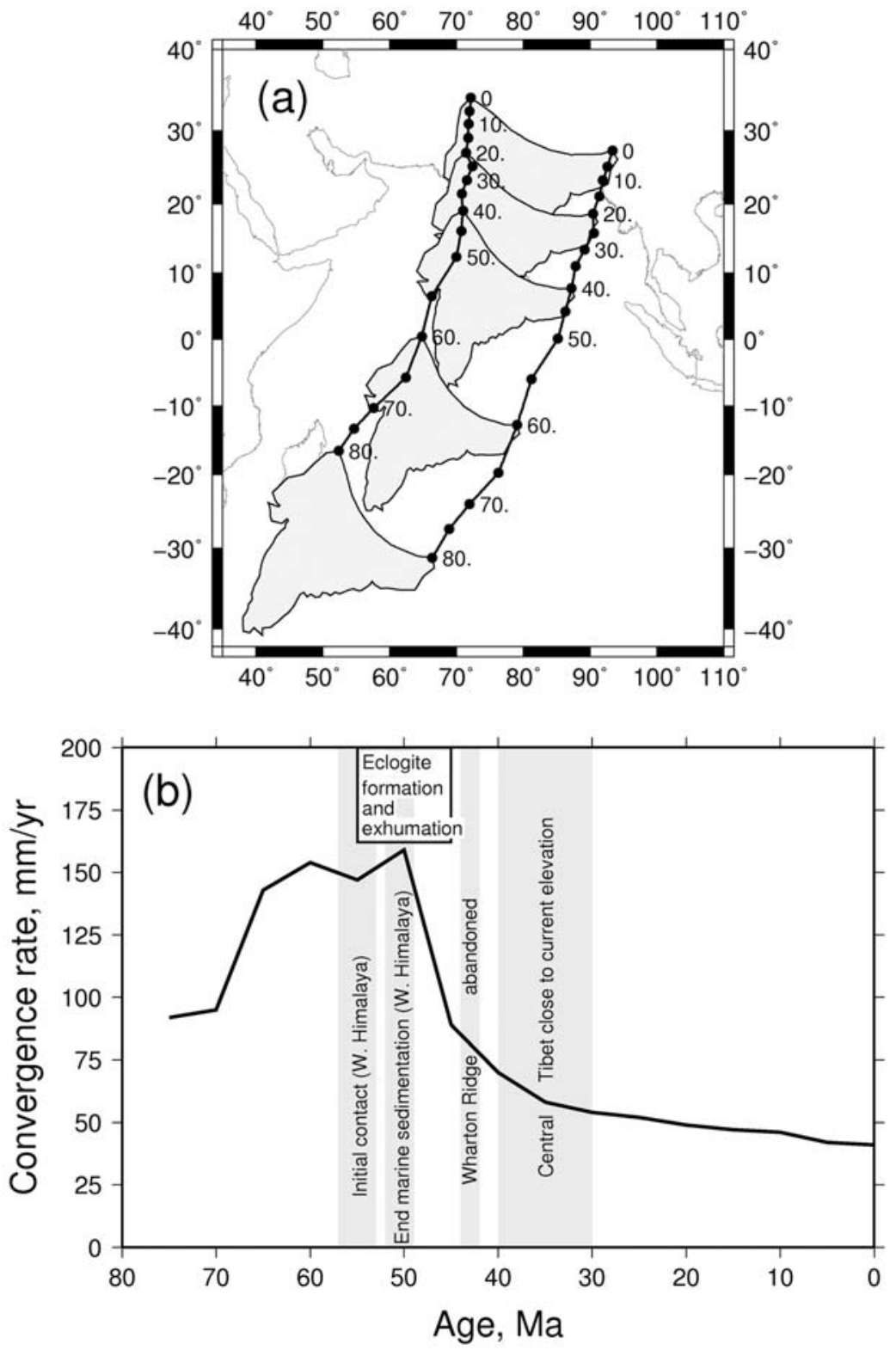

Figure 1. (a) The black lines show the positions since $80 \mathrm{Ma}$, in a Eurasia-fixed reference frame, of points currently located on the Indian plate near the east and west Himalayan syntaxes (calculated from the plate reconstructions described in section 2). Positions are labeled with the time in Myr. The reconstructed locations of the present-day outline of the Indian subcontinent are shown at $20 \mathrm{Ma}$ increments. (b) The black line shows the rate of convergence between India and Asia since $75 \mathrm{Ma}$ (at a point currently located at $28^{\circ} \mathrm{N}, 80^{\circ} \mathrm{E}$ ). The gray bands show the timings of notable events in the history of the India-Asia collision. Also shown are the timings of eclogite formation and exhumation [e.g., de Sigoyer et al., 2000; Guillot et al., 2003], which probably record the end of subduction in the region. The collision is thought to have begun at the western part of the plate boundary (i.e., the dates shown here for the initial contact of the continental margins and the end of marine sedimentation) and propagated eastward over the subsequent 5-10 Ma [e.g., Rowley, 1996].

[2005] for the motion of India relative to Capricorn (across the region of slow and diffuse deformation in the Indian Ocean) and Capricorn relative to Somalia at times since $20 \mathrm{Ma}$. For older ages, we use the Capricorn-Somalia reconstructions of Royer and Patriat [2002]. Lemaux et al. [2002] obtained an estimate for the opening of the East African Rift. We used the NW Africa-North America reconstructions of Müller et al. [1999], and the North America-Eurasia rotations of Gaina et al. [2002] and Merkouriev and DeMets [2008]. Table A1 in Appendix A lists the rotation parameters of Royer and Patriat [2002], which at present are not easily accessible in the literature, and gives the rotation poles of India relative to Asia that we obtained from the reconstructions. The most prominent 


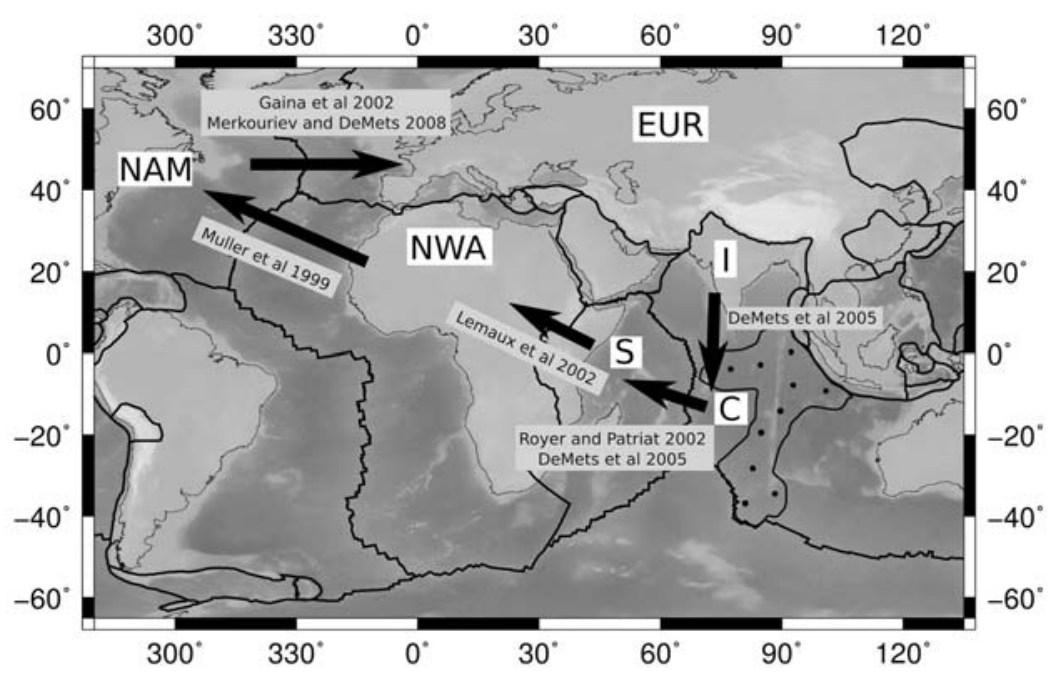

Figure 2. The plate circuit used to derive the velocity of India relative to Asia shown in Figure 1. The dotted area shows a region of diffuse deformation in the northeast Indian Ocean [e.g., Gordon et al., 1998]. Plate boundaries are from Bird [2003]. Abbreviations are I, India; C, Capricorn; S, Somalia; NWA, northwest Africa; NAM, North America; EUR, Eurasia. When computing the convergence velocity between India and Asia, we have taken account of the relatively minor and diffuse deformation between the Indian and Capricorn "subplates." However, when performing force balance calculations for the plate, we have assumed that the plate boundary stresses are transmitted across this region and that entire "Indo-Australian" plate behaves in a rigid manner.

feature of our reconstruction is the sudden decrease in velocity at $\sim 50 \mathrm{Ma}$, followed by a more gradual decrease until $\sim 35 \mathrm{Ma}$ (Figure 1). This slowdown occurred at the time of a major reorganization of plate boundaries in the Indian Ocean. The Wharton mid-ocean ridge was abandoned (WR on Figure 3a), active spreading ceased in the northeastern Indian Ocean, and the Indian plate approximately tripled in size to include the region of the Australian continent [e.g., Liu et al., 1983]. This present-day plate is also referred to as the Indo-Australian plate, but in this paper "Indian plate" is taken to mean the plate that, at the time in question, includes the Indian continent. In what follows, we will refer to the situation of the Indian plate before the rearrangement of plate boundaries and mountain building in Tibet as the "precollision" plate. The configuration after the abandonment of the Wharton ridge and the growth of the Tibetan Plateau is referred to as the "postcollision" plate.

[5] Our reconstructions additionally show that the Euler pole of India in the hot spot reference frame moved east by $\sim 40^{\circ}$ during the time interval when the rate of convergence relative to Asia decreased and the plate boundaries became reorganized. The small white triangles in NW Africa shown on Figure 3a show two estimates for the Euler pole of the precollision Indian plate. The poles are averaged over the time interval 51.74-64.75 Ma (magnetic anomalies 23o to 29 o) in order to remove the effects of shorter-timescale variations, probably related to uncertainties in the plate reconstructions. During this time the plate velocity in the hot spot reference frame was uniformly high. The northeastern triangle is an estimate of the pole position obtained from the plate circuit: India-Central Indian Basin [DeMets et al., 2005], Central Indian Basin-East Africa [DeMets et al., 2005; Royer and Patriat, 2002] (see Appendix A), East Africa-East Antarctica [Royer and Chang, 1991;
Bernard et al., 2005], East Antarctica-West Antarctica [Cande et al., 2000], West Antarctica-Pacific [Cande et al., 1995], Pacific-hot spots [Wessel et al., 2006]. The southwestern triangle was obtained using the poles of relative motion between the Central Indian Basin and east Antarctica directly [Royer and Chang, 1991; Müller et al., 1997], rather than using the circuit India-Africa-Antarctica, and then following the same plate circuit as above. Poles from both plate circuits have been shown to give an indication of the likely uncertainties in pole position. The small black diamonds in NE Africa show the Euler pole locations from plate reconstructions averaged over the time period 0-26.55 $\mathrm{Ma}$ (magnetic anomaly 80), when the motion of India was uniformly low. The northwestern pole represents the plate circuit via Africa, as described above, and the southeastern pole represents the reconstruction using the circuit not involving Africa.

[6] We have compared our plate reconstruction with the one published recently by Molnar and Stock [2009]. Both models show a significant decrease in convergence rate at $\sim 50 \mathrm{Ma}$, but differ for more recent times. These differences are due to the fact that (1) we use different plate reconstructions in the Indian Ocean (using the circuit IndiaCapricorn-Somalia [Royer and Patriat, 2002; DeMets et al., 2005], rather than India-Somalia directly [Molnar et al., 1988; Merkouriev and DeMets, 2006], and (2) we use the central and north Atlantic reconstructions of Müller et al. [1999] and Gaina et al. [2002], rather than those of McQuarrie et al. [2003] (which are based upon Klitgord and Schouten [1986], Srivastava and Tapscott [1986], and Srivastava et al. [1990]). Both studies use the north Atlantic reconstructions of Merkouriev and DeMets [2008] for the time 0-20 Ma. Appendix A shows in detail the differences in convergence rate calculated from our reconstructions and those of Molnar and Stock [2009], and the relative effects of 

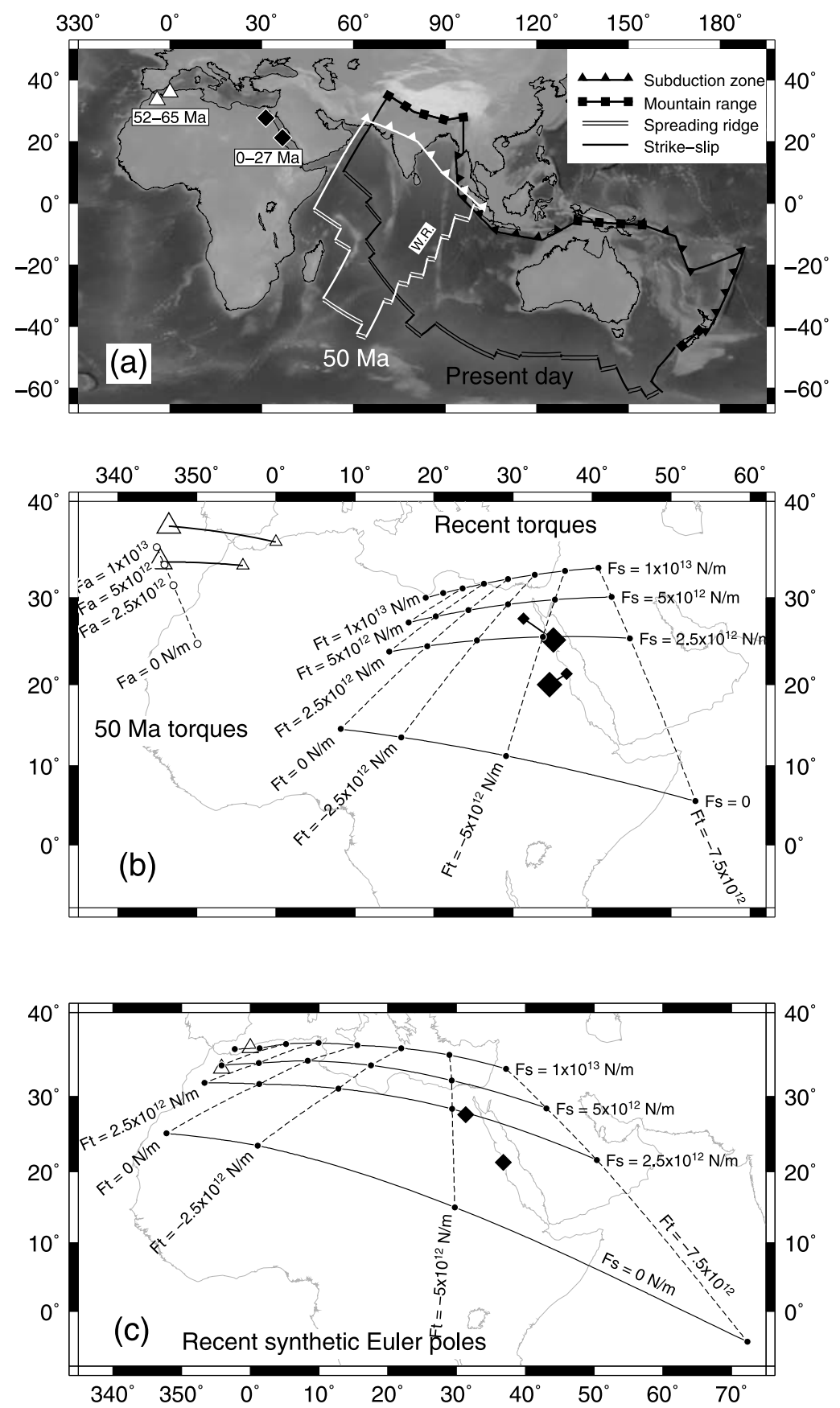

Figure 3. (a) The geometry of the Indian plate at $50 \mathrm{Ma}$ (in white) and at the present-day (in black). The Wharton mid-ocean ridge is labeled WR in the 50 Ma geometry. The white triangles in NW Africa show Euler poles for India in the hot spot reference frame for the time $\sim 52-65 \mathrm{Ma}$, from the plate reconstructions described in the text. The black diamonds in NE Africa also show Euler poles for India in the hot spot reference frame but for the time $\sim 27-0 \mathrm{Ma}$. (b) The large triangles and diamonds, joined to the smaller Euler pole symbols by black lines, show the orientations of the corresponding basal drag torques. The white circles show the orientations of the plate boundary torques for the precollision plate geometry. Fa represents the force per unit length applied to the Indian plate by the subduction zone beneath Asia on the northeastern margin of the plate. The black circles show the plate boundary torques for the postcollision geometry. Fs corresponds to the force per unit length applied to the Indian plate by subduction zones, not including the plate boundary segment currently occupied by the Tibetan Plateau. Ft corresponds to the force per unit length applied by the plate boundary segment that corresponds to the present-day Tibetan Plateau (with negative values indicating a force directed southward, resisting the current motion of the plate). For the postcollision torques, solid lines represent lines of constant subduction zone force, and dashed lines represent lines of constant force from the region of Tibet. (c) Synthetic Euler poles, calculated as described in the text, for the modern plate geometry. 
using alternative rotation parameters in the Atlantic and Indian oceans. Our reconstructions do not show the significant velocity change at $\sim 20$ Ma described by Molnar and Stock [2009], and in this paper we concentrate our attention on the possible causes of the major velocity change that occurred between $\sim 50$ and $\sim 35$ Ma.

[7] The elevation history of the Tibetan Plateau is a source of much debate. Some authors have argued that the current elevation of the plateau was acquired significantly later than the onset of collision, possibly at 7-10 Ma, and would have been the cause of the strengthening of the Indian monsoon at that time [e.g., Molnar et al., 1993]. Molnar and Stock [2009] review the evidence for increased tectonic activity on the margins of the Tibetan Plateau since $\sim 15 \mathrm{Ma}$, which they suggest may be related to elevation changes in the central plateau. However, recent geological evidence points to an earlier date of uplift. Aikman et al. [2008] suggested that significant crustal thickening had occurred prior to $44 \mathrm{Ma}$, and Rowley and Currie [2006] documented elevations in central Tibet which are similar to the present-day using samples dated at $\sim 35 \mathrm{Ma}$. In addition, climate models have shown that the changing distribution of the Neotethys Sea has as important an effect on monsoon intensity as mountain building in Tibet [e.g., Ramstein et al., 1997; Fluteau et al., 1999], so the Late Miocene strengthening of the monsoon is not necessarily an indicator of coeval uplift in Tibet. Given the agreement between Rowley and Currie's [2006] estimate of when the plateau attained close to the current elevation and the date at which the India-Asia convergence stabilized, we rather test the hypothesis that the growth of topography in Tibet can explain the dramatic change in India's motion at $\sim 50-35 \mathrm{Ma}$.

\section{Forces Exerted Upon the Indian Plate}

\subsection{Mid-ocean Ridges}

[8] Young oceanic lithosphere formed at mid-ocean ridges is hotter than the lithosphere beneath old seafloor, so the surface lies at higher elevations. As a result, at depths above the level of isostatic compensation, the pressure is higher below ridges than below older seafloor. The magnitude of the pressure difference, and hence the horizontal "ridge-push" force that the ridges exert upon the surrounding plates, can be estimated using a plate cooling model [e.g., Parsons and Richter, 1980]. The torque about the center of the Earth which results from ridge push can therefore be calculated by integrating over the area of the plate the potential energy differences due to cooling (using the seafloor age distribution [Müller et al., 2008a]). A simpler alternative approach consists of treating ridge push as a force on the margin of the plate, acting perpendicular to the ridge. We have compared the two approaches and found that for the present-day Indian plate the two methods yield approximately the same estimate if the line force is taken to be $\sim 3 \times 10^{12} \mathrm{~N}$ per unit length parallel to the ridge, a value similar to previous estimates [e.g., Parsons and Richter, 1980]. For the precollision Indian plate the seafloor age is poorly known in some regions, such as the now consumed Tethyan ocean floor north of continental India. However, the locations of the active ridge segments are relatively well known [e.g., Müller et al., 2008b], so in the calculations below we estimate the effect of ridge push on the precolli- sion plate using only the simplified approximation of line forces.

\subsection{Mountain Belts}

[9] As is the case with mid-ocean ridges, mountain belts represent areas of isostatically compensated topography. As such, they exert a force upon the neighboring plates [e.g., Artyushkov, 1973]. The magnitude of this force can be estimated by considering the potential energy differences between the mountains and the adjacent lowlands, which can be calculated using elevation and crustal thickness contrasts [e.g., Molnar and Lyon-Caen, 1988]. We have estimated the potential energy difference between the mountains and lowlands of New Guinea and of the southern island of New Zealand. According to these calculations, the mountain belts exert a force upon the Indian plate of $\sim 4 \times$ $10^{12} \mathrm{~N} / \mathrm{m}$ and $\sim 2 \times 10^{12} \mathrm{~N} / \mathrm{m}$, respectively (Appendix $B$ gives details of the calculations). The locations where these forces were applied our calculations are shown by the plate boundary segments marked with black squares on Figure 3a. The magnitude of the force exerted upon the Indian plate by the Tibetan Plateau has been varied in our calculations.

\subsection{Subduction Zones}

[10] As subducting slabs sink into the mantle, the relatively high density of the cool material results in a gravitational force that acts to move the plates toward the subduction zones. It is possible to calculate the density anomaly associated with sinking slabs using models for the temperature structure. However, the resistive forces exerted on the subducting slab and the stresses associated with the bending of the plate also need to be taken into account. These quantities can have a large effect upon the force balance of subduction zones [e.g., Conrad and Hager, 1999; Billen and Gurnis, 2001], but are relatively poorly known. The magnitude of the net force exerted by subduction zones upon the neighboring plates is therefore not well known. For example, some authors have estimated that the gravitational force due to the mass of the slab is almost entirely balanced by local resisting forces [e.g., Forsyth and Uyeda, 1975; Richardson, 1992], while, on the contrary, others have suggested that the majority of the forces driving plate motions arise from subduction zones [e.g., LithgowBertelloni and Richards, 1995].

[11] For simplicity, we have assumed that the net force per unit length exerted upon the Indian plate is the same along all of the boundaries where the plate is subducting. We have then varied the magnitude of this force. The buoyancy force and the depth extent of seismicity both depend on temperature [e.g., Emmerson and McKenzie, 2007]. We are therefore encouraged in our assumption by the similar distribution of seismicity with depth along the boundaries where the Indian plate subducts: continuous seismic zones typically extend to depths of $200-300 \mathrm{~km}$, and a small number isolated earthquakes are seen deeper than $500 \mathrm{~km}$ [Engdahl et al., 1998]. The exception is in the southeastern $\sim 2500 \mathrm{~km}$ of the subduction zone that extends from New Guinea to mainland Asia, which comprises roughly a quarter of the length of subducting Indian plate. Here, a continuous seismic zone extends from the surface to depths of $600-$ $700 \mathrm{~km}$ [Engdahl et al., 1998]. 
[12] In addition, we have used the estimates of Lamb [2006] for the magnitudes of the forces transmitted across the Tonga and Hikurangi subduction zones, where the Pacific plate subducts beneath the eastern margin of the Indian plate.

\subsection{Strike-Slip Boundaries}

[13] Morgan and Parmentier [1984] studied the stress state at the intersection of mid-ocean ridges and transform faults and inferred that the forces transmitted across the transform faults must be relatively small. Most large continental strike-slip faults have also been shown to be relatively weak [e.g., Mount and Suppe, 1992]. In our study, we estimate the force transmitted across strike-slip faults, including transform faults on mid-ocean ridges, assuming a constant shear stress of $20 \mathrm{MPa}$ (similar to stress drops observed in earthquakes) extending from the surface to $20 \mathrm{~km}$ depth. Accordingly, the force per unit length transmitted across strike-slip boundaries is less than one fifth of that resulting from mid-ocean ridges. Because the magnitude of this force is small, varying it to be either zero, or double the value we estimate here, has only a small effect on the results of our calculations.

\subsection{Basal Tractions}

[14] The magnitude of the traction exerted on the base of the plates by relative motion between the surface and the underlying mantle is particularly poorly known. Measurements of seismic anisotropy at depths that correspond to the base of the Indian lithosphere (e.g., $200-250 \mathrm{~km}$ in the continents and $100-150 \mathrm{~km}$ in the oceans) show anisotropy with the fast propagation direction aligned with the absolute plate motion direction [e.g., Leveque et al., 1998; Debayle et al., 2005]. These observations suggest that shear in the asthenosphere, accommodating relative motion between the lithosphere and deeper mantle, is creating the anisotropic signature. The anisotropy also suggests that local variations in the direction of mantle flow due to the complexities of mantle dynamics may be neglected to the first order. Therefore, for simplicity we assume that the tractions on the base of the plate everywhere act parallel to the motion of the plate relative to the mantle, which is assumed fixed with respect to the hot spot reference frame. However, it is not possible to determine from seismic observations whether the basal drag is a driving or resisting force. It is also unclear if the asthenosphere has a Newtonian or non-Newtonian rheology, and so if the tractions are linearly or nonlinearly proportional to the plate velocity. For simplicity we assume a Newtonian rheology and then examine the validity of this assumption in section 5.2.

\section{Balance of Forces on the Indian Plate}

\subsection{Calculation of Torques}

[15] Since accelerations in the solid Earth are negligible, the net torque resulting from all the forces exerted on the Indian plate must be zero. This means that the net torque resulting from all the plate boundary forces (the "plate boundary torque") must balance the torque resulting from the basal tractions, which we call the "basal drag torque."

[16] The torque about the center of the Earth resulting from a force acting upon a plate is given by $\mathbf{T}=\int \mathbf{r} \times \mathbf{f} d l$, where $r$ is the radius vector to the point where the force is applied, and $\mathbf{f}$ is the force. For plate boundary forces the integration is along the length of the plate boundary being considered, and for basal tractions the integration is over the area of the plate. The computation of the torques resulting from the various plate boundary forces described in section 3 is straightforward. We represent the orientations of these torques on maps by showing the location at which the torque vectors, originating from the center of the Earth, would intersect the surface.

[17] We use Euler poles of India in the hot spot reference frame to calculate the torque vector that results from the motion of the Indian plate relative to the underlying mantle. We assume the asthenosphere has a uniform viscosity. We have varied the magnitudes of the resisting force due to the India-Asia collision and the driving force exerted by subduction zones. Each configuration of forces gives a different orientation for the plate boundary torque. We can therefore test which distribution of plate margin forces gives a plate boundary torque with the same orientation as the basal drag torque that is derived from the results of plate reconstructions. This is the configuration of plate margin forces which is consistent with the observed plate motion. We can then infer the asthenospheric viscosity required for the magnitudes of the two torques to balance each other. Given that driving forces are applied to the plate by mid-ocean ridges and subduction zones, and considering the likely values of the resisting forces generated by crustal thickening in Tibet, we find that for the plate boundary and basal drag torques to balance, the tractions on the base of the plate must act to resist plate motions.

[18] Figure 3a shows the precollision and postcollision geometry of the Indian plate. The precollision geometry was constructed using the paleoseafloor age data of Müller et al. [2008b]. The details of the geometry for both ages considered have been simplified, especially where ridges are offset by many transforms. However, the approximate lengths and orientations of the different types of plate boundary have been preserved. Figure $3 \mathrm{~b}$ shows the Euler poles (in the hot spot reference frame) and basal drag torque orientations of the precollision and postcollision Indian plates. The small white triangles in NW Africa show two estimates of the location of the Euler pole for the time period 51.7464.75 Ma, as described earlier. The larger white triangles that are joined by lines to the Euler poles show the corresponding orientations of the basal drag torques. The small diamonds in NE Africa show the Euler poles for the time period 26.55-0 Ma. As before, the larger symbols show the orientations of the torques that result from basal drag.

\subsection{Constraints on Plate Boundary Forces for the Precollision and Postcollision Indian Plates}

[19] Here we test which distribution of plate margin forces gives a plate boundary torque with the same orientation as the basal drag torque, as derived from the plate motion of India. We consider separately the precollision and postcollision situations.

[20] For the precollision configuration we have varied the net force per unit length applied to the Indian plate by the subduction zone on its northeastern margin. Because the ridges and subduction zone boundaries are roughly parallel, changing the force exerted upon the plate by the 
subduction zone (Fa on Figure $3 \mathrm{~b}$ ) does little to change the orientation of the plate boundary torque (small white circles on Figure $3 b$ ). If the subduction zone force is $\sim 2.5 \times$ $10^{12} \mathrm{~N}$ or greater (per unit length along-strike), the plate boundary and basal drag torques have similar orientations. Therefore, for these subduction zone forces, the plate margin forces are consistent with the observed motion of the precollision Indian plate. Given the potential errors in the Euler pole and plate boundary locations, we do not believe we can reliably discriminate between the different net subduction zone forces equal to or greater than $\sim 2.5 \times$ $10^{12} \mathrm{~N} / \mathrm{m}$.

[21] There is more variation in the orientations of the ridges, subduction zones, and mountain belts on the margins of the modern Indian plate. Therefore, changing the magnitude of the net force from the subduction zones has a larger effect on the orientation of the plate boundary torque (small black circles on Figure 3b). We have also varied the force applied by the region of the Tibetan Plateau (from the value applied at the subduction zone boundaries, to a resistive force resulting from the presence of a mountain belt). The orientations of the plate boundary and basal drag torques are in closest agreement if the force exerted by the Tibetan Plateau upon the Indian plate ( $\mathrm{Ft}$ in Figure $3 \mathrm{~b}$ ) is a resistive force of $\sim 5-6 \times 10^{12} \mathrm{~N} / \mathrm{m}$. In addition, the best match is found if the net force from the subduction zones, not including the now inactive subduction zone in the region of Tibet, is a driving force of $\sim 2-2.5 \times 10^{12} \mathrm{~N} / \mathrm{m}$ (Fs in Figure 3b).

[22] To give an indication of the errors that may have been introduced by our choices for some of the plate margin forces, we have shown the results of some alternative calculations in Figures $\mathrm{S} 1-\mathrm{S} 4$ in the auxiliary material. ${ }^{1}$ In these calculations we have varied the force transmitted across strike-slip boundaries to be absent or doubled from the values used above. We have also changed the force exerted by the mountains of New Guinea and southern New Zealand to be $30 \%$ more and $30 \%$ less than used above. All of these changes have only minor effects on the results of the calculations, because the changes in force are small compared with the total magnitude of the other forces acting upon the plate.

\subsection{Tractions Applied to the Base of the Indian Plate}

[23] For the forces on the plate to balance, the plate boundary and basal drag torques should have the same orientations and amplitudes but opposite signs (since the two vectors must add to zero). The magnitude of the plate boundary torque therefore constrains the magnitude of the basal drag torque, and allows us to estimate the tractions applied to the base of the plate. For the postcollision Indian plate, the basal drag is required to result in a torque of $\sim 1.8 \times 10^{26} \mathrm{Nm}$, at $25.6^{\circ} \mathrm{N} 33.8^{\circ} \mathrm{E}$, in order to balance the plate boundary torque (according to our preferred model for the plate boundary forces). This corresponds to an average basal traction of $\sim 0.47 \mathrm{MPa}\left(\tau_{\text {post }}\right)$, associated with an average plate velocity of $\sim 50 \mathrm{~mm} / \mathrm{yr}\left(V_{\text {post }}\right)$. For the precollision configuration, a torque of $1.6 \times 10^{26} \mathrm{Nm}$, at $31.3^{\circ} \mathrm{N}$

\footnotetext{
${ }^{1}$ Auxiliary materials are available in the HTML. doi:10.1029/ 2009JB006634.
}

$13.0^{\circ} \mathrm{W}$, is required to balance the plate margin forces, implying an average basal traction of $\sim 1.1 \mathrm{MPa}\left(\tau_{\text {pre }}\right)$. This value of basal traction is associated with an average plate velocity of $\sim 137 \mathrm{~mm} / \mathrm{yr}\left(V_{\text {pre }}\right)$. The factor $\tau_{\text {post }} / V_{\text {post }}=$ $3.0 \times 10^{14}$ is similar to the factor $\tau_{\text {pre }} / V_{\text {pre }}=2.5 \times 10^{14}$. Therefore, although the tractions we calculate are higher for the precollision plate, the difference is likely due to the difference in the plate velocity at the two times. The close to linear relation between basal tractions and plate velocity is consistent with our assumption of a Newtonian rheology for the asthenosphere. The tractions we have calculated are used in section 5 to estimate the viscosity of the asthenosphere.

\section{Implications for the Rheology of the Asthenosphere}

\subsection{An Estimate of the Viscosity}

[24] To estimate the viscosity of the asthenosphere we adopt the view that the basal traction results from simple shear of a thin low-viscosity layer beneath the plate. In this case the viscosity is simply $\eta=\tau /(v / h)$, where $\tau$ is the average traction on the base of the plate, $v$ is the average velocity of the plate relative to the underlying mantle, and $h$ is the thickness of the layer. Figures $4 \mathrm{a}$ and $4 \mathrm{~b}$ show our estimates for the viscosity of the asthenosphere for the precollision and postcollision configurations. The results of the calculations for the two different times are in good agreement. Our preferred values for the subduction zone force, as estimated above based on plate boundary torque orientations, are shaded in gray on Figure 4. Our study does not allow any constraints to be placed upon the thickness of the asthenosphere. In Figure 4 the preferred range is taken from Craig and McKenzie [1986] and Robinson and Parsons [1988], who, on the basis of topography and geoid anomalies in the oceans, estimated the thickness to be $150 \mathrm{~km}$ and $100-150 \mathrm{~km}$, respectively. This range is in agreement with the $\sim 125 \mathrm{~km}$ thickness of the seismically anisotropic layer beneath the Australian continent which was found to have a fast axis parallel to the direction of absolute plate motion [Debayle et al., 2005]. For an asthenosphere thickness of $100-150 \mathrm{~km}$, and a net force from the subduction zones of $\sim 2.5 \times 10^{12} \mathrm{~N} / \mathrm{m}$, we estimate the viscosity of the asthenosphere to be in the range $\sim 2-5 \times 10^{19} \mathrm{~Pa} \mathrm{~s}$.

\subsection{Newtonian or Non-Newtonian Rheology}

[25] The torques and Euler poles presented above were computed under the assumption of a Newtonian rheology for the asthenosphere, i.e., a linear relation between basal traction and plate velocity. However, it is unclear if the asthenosphere behaves in a Newtonian or non-Newtonian manner, and therefore if our assumption regarding the rheology is correct. Studies of postglacial rebound suggest that the asthenosphere has a Newtonian rheology [e.g., Karato and $W u, 1993]$. However, the presence of seismic anisotropy suggests that dislocation creep is occurring to some extent, in which case it may be more appropriate to assume a non-Newtonian rheology. It is possible that this seeming disagreement may be the result of vertical rheological stratification. To test the effect on the results presented above of using an alternative rheology, we have performed the same calculations assuming a nonlinear viscosity. In this case we assume that the basal traction is 
(a) 50 Ma plate geometry Newtonian rheology

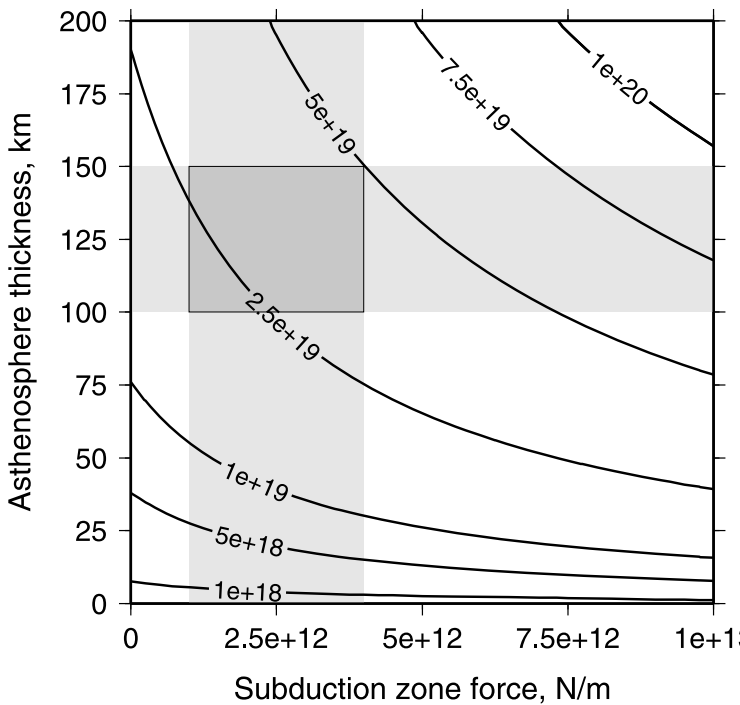

(c) 50 Ma plate geometry

Non-Newtonian rheology

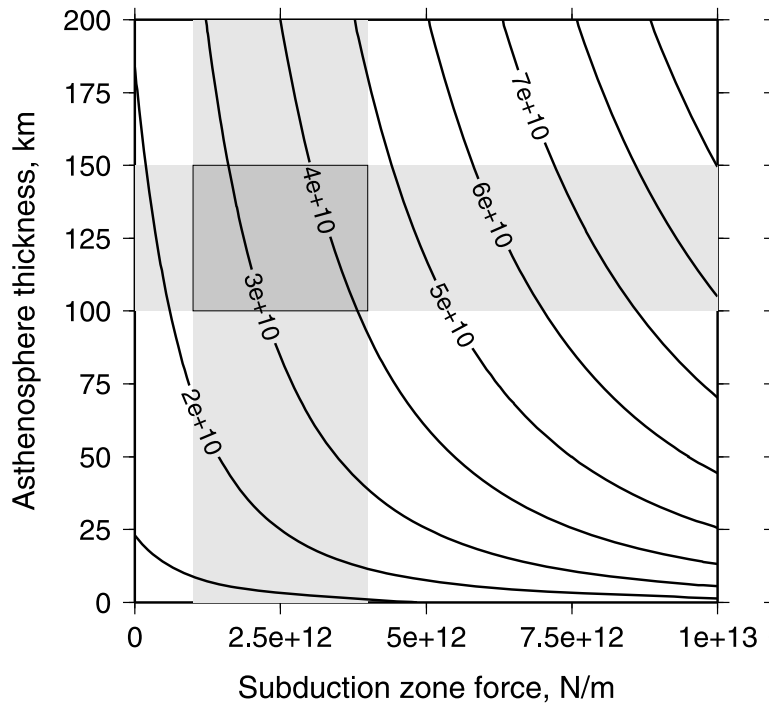

(b) Modern plate geometry, $F_{\text {Tibet }}=5 \times 10^{12} \mathrm{~N} / \mathrm{m}$ Newtonian rheology

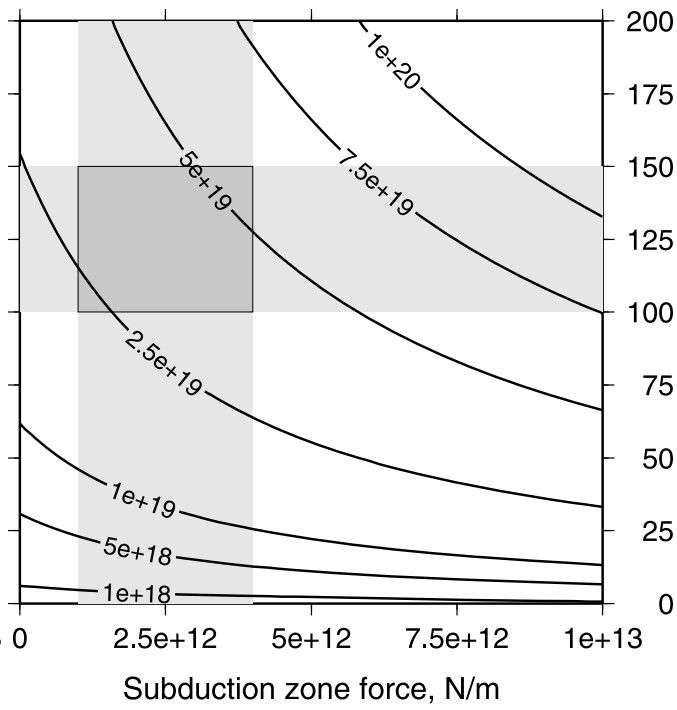

(d) Modern plate geometry, $F_{\text {Tibet }}=5 \times 10^{12} \mathrm{~N} / \mathrm{m}$ Non-Newtonian rheology

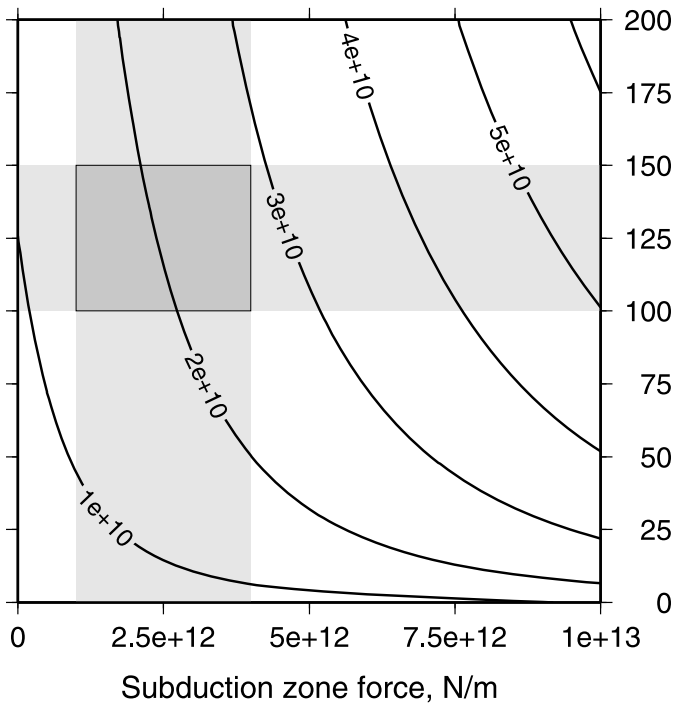

Figure 4. Our estimates of asthenosphere properties as a function of the force exerted upon the Indian plate by subduction zones and of the thickness of the asthenosphere. (a) Viscosity estimates from calculations for the precollision Indian plate, assuming a Newtonian rheology. (b) Viscosity estimates for the postcollision plate, also assuming a Newtonian rheology (the force exerted upon the Indian plate by the Tibetan Plateau is taken to be $5 \times 10^{12} \mathrm{~N} / \mathrm{m}$ ). Our preferred values of the subduction zone force and asthenosphere thickness are shaded gray (as described in the text). (c and d) Our precollision and postcollision estimates for the value of the parameter $B$ in the equation $\tau=B(v / h)^{\frac{1}{n}}$, if $n$ is 3 (section 5.2).

proportional to $V^{\frac{1}{n}}$, where $V$ is the velocity at a given point and $n$ is the stress exponent from the constitutive law for a non-Newtonian fluid ( $\tau=B E^{\frac{1}{n}-1} \dot{\epsilon}$, where $\tau$ is the deviatoric stress tensor, $B$ is a constant, $E$ is the second invariant of the strain rate tensor, and $\dot{\epsilon}$ is the strain rate tensor). Experimental results [e.g., Hirth and Kohlstedt, 2003] show that for olivine deforming by diffusion creep, $\mathrm{n}=1$ and the rheology is Newtonian. For dislocation creep, $\mathrm{n} \sim 3$. We have calculated basal drag torques for the case where $\mathrm{n}=3$, and found that for the two plate configurations considered here, the basal drag torques have orientations that differ by only a few degrees from those computed assuming a Newtonian rheology. This agreement is because the distribution of velocities is roughly symmetric about the "equator" from the Euler pole. However, if we assume a nonlinear viscosity the difference in basal tractions between the precollision and postcollision plates cannot be easily reconciled with the same rheology. Figures $4 \mathrm{c}$ and $4 \mathrm{~d}$ show the values of the parameter $B$ in the equation $\tau=B(v / h)^{\frac{1}{n}}$, if $\mathrm{n}$ is 3 . As can be seen, a single value of $B$ is not compatible 


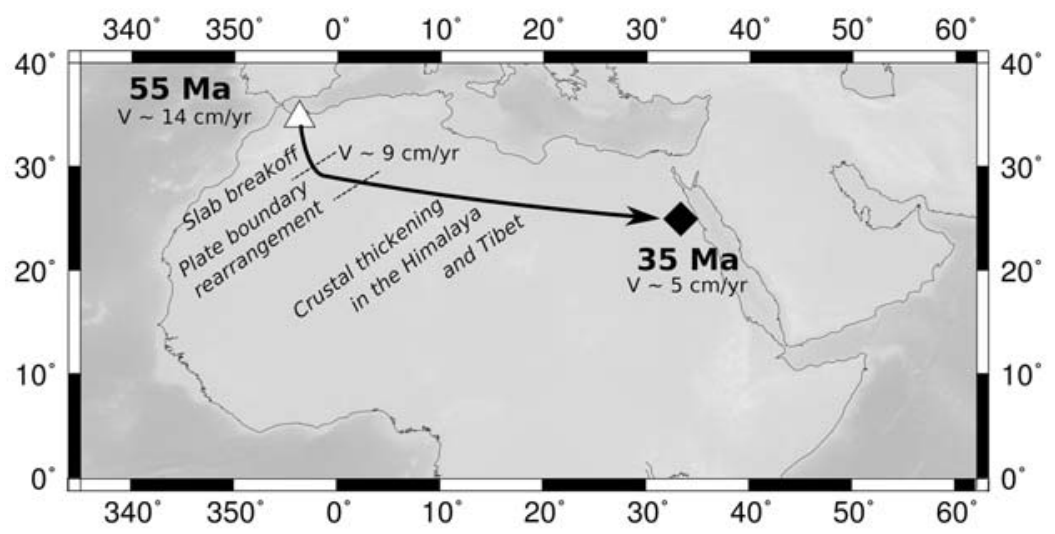

Figure 5. A schematic representation of the Cenozoic motion of the Euler pole of the Indian plate relative to the underlying mantle. The effects of slab break off in Tibet, the rearrangement of plate boundaries in the Indian Ocean, and mountain building in the Tibetan Plateau are indicated.

with the velocities of both the precollision and postcollision Indian plates, suggesting that our choice of a Newtonian rheology was more appropriate.

\section{Discussion}

\subsection{Causes of the Cenozoic Slowdown of the Indian Plate}

[26] The analysis presented above can be used to estimate the extent to which the cessation of subduction along the southern Tibetan margin, and mountain building in central Asia, may have affected the kinematics of the Indian plate. In that regard, it is instructive to consider Figure $3 \mathrm{~b}$ and synthetic Euler poles (relative to the underlying mantle) that are computed for the modern plate geometry and plotted in Figure 3c. These synthetic poles were calculated by estimating the plate boundary torque corresponding to various values of the resisting force applied along the Himalayan collision zone and of the net subduction zone force, and then finding the location of the Euler pole that would result in a basal drag torque with the same orientation. This plot shows that, for the postcollision plate geometry, the location of the synthetic pole is shifted eastward toward the location of the postcollision Euler pole as the resisting force from Tibet is increased. The date of formation of the eclogites currently exposed in the Himalayas [e.g., de Sigoyer et al., 2000] suggests that slab break off in Tibet occurred before the rearrangement of plate boundaries in the Indian Ocean [e.g., Liu et al., 1983]. During slab break off, the Euler pole of India relative to the underlying mantle would be expected to move SSE, away from the precollision poles. The direction of motion would have a similar azimuth to the line of precollision plate boundary torques shown as white circles on Figure $3 \mathrm{~b}$. At this time, the plate has its precollision geometry, but no force is exerted upon it by the region which will become the Tibetan Plateau. Therefore, when the plate boundaries in the Indian Ocean changed geometry, the pole would move from its position SSE of the precollision poles, to the line labeled $\mathrm{Ft}=0$ in Figure $3 \mathrm{c}$. The plate now has its post collision geometry, but with no force exerted upon it by the region of Tibet. The position of the pole along the line $\mathrm{Ft}=0$ depends on the force exerted upon the plate by the subduction zones along the other margins (not including the now inactive subduction zone beneath Tibet). During mountain building in Tibet, the pole will then move eastward, from the line labeled $\mathrm{Ft}=0$, to the line labeled with the current force exerted by Tibet upon India $(\sim 5-6 \times$ $10^{12} \mathrm{~N} / \mathrm{m}$ ). If the force exerted upon the plate by the subduction zones on its other margins remains constant, the pole will follow a line of constant subduction zone force ( $\sim \mathrm{E}-\mathrm{W}$ solid lines in Figure $3 \mathrm{c})$. As can be seen, this latter motion accounts for most of the change in Euler pole location between the precollision and postcollision configurations (shown schematically in Figure 5). It therefore seems that mountain building in Tibet accounts for most of the change in motion of India during the Cenozoic. It is likely that the effects which contributed to the slowdown of the Indian plate did not occur sequentially, as assumed in this discussion, but at overlapping times (Figure 1). In this case the Euler pole would not be expected to have followed the precise track described, but the general trajectory would have been similar, and relative importance of the effects would have been the same as described.

[27] As described above, a notable feature of the tectonic history of the Indian Ocean is the rearrangement of plate boundaries on the southern and eastern margins of the Indian plate which occurred around the same time as continent-continent collision and mountain building in the region of the Tibetan Plateau (Figure 1). It is possible that this may be a coincidence, but we believe it more likely that, as suggested by Liu et al. [1983], the changing forces on the plate due to the collision in Tibet resulted in the change in plate geometry. When continent-continent collision began in the region of Tibet, the resulting change of forces on the northern margin of the Indian plate will likely have lead to movement of the poles of relative rotation between the Indian plate and the surrounding plates. The Wharton Ridge was offset by a relatively large number of right-lateral and large-offset transform faults (Figure 3). If the pole of rotation of the Indian plate relative to the plate containing Australia moved, then these transforms would no longer be ideally oriented to accommodate the relative motion between the plates. We suspect that the location of the active ridge may therefore have jumped to between the 
Kerguelen Plateau and the Broken Ridge, and connected with the ridge south of Australia where spreading was already occurring [e.g., Cande and Mutter, 1982], because this was energetically more favorable than breaking new transform faults along the Wharton Ridge.

\subsection{Constraints on the Magnitudes of Plate Boundary Forces}

[28] Our estimate for the magnitude of the force exerted by the Tibetan Plateau upon the Indian plate $(5-6 \times$ $10^{12} \mathrm{~N} / \mathrm{m}$ ) is similar to that which would be expected from considering isostatically compensated crustal thickness contrasts $\left(\sim 7 \times 10^{12} \mathrm{~N} / \mathrm{m}\right.$ [e.g., Molnar and Lyon-Caen, 1988]). The force exerted upon the Indian plate by the Tibetan Plateau is therefore considerably larger than the forces on any of the other boundaries. However, because the mountains form only a small part of the boundary of the plate, they can be supported by the lower forces exerted upon the other plate margins (as pointed out by Sandiford et al. [1995]). Our estimate for the net subduction zone force is similar in magnitude to the force exerted upon regions of old seafloor by mid-ocean ridges $\left(2.5-3 \times 10^{12} \mathrm{~N} / \mathrm{m}\right)$. Our results are consistent with those of Coblentz et al. [1995, 1998] and Reynolds et al. [2002], who showed that to match the stress field within the Australian continent, the subduction zone force had to be similar to or smaller than the magnitude of ridge push.

\subsection{Constraints on the Rheology of the Asthenosphere}

[29] Our study suggests that the tractions on the base of the Indian plate are due to shear in the asthenosphere, and resist the motion with respect to the deeper mantle. We find that, given the decrease of the velocity of India with respect to the hot spot reference frame, a Newtonian rheology is consistent with the difference in basal tractions for the precollision and postcollision plates. The inferred viscosity of $\sim 2-5 \times 10^{19} \mathrm{~Pa} \mathrm{~s}$, for a $100-150 \mathrm{~km}$ thick asthenosphere, compares reasonably well with independent estimates. For example, the magnitude of geoid anomalies at oceanic fracture zones lead Craig and McKenzie [1986] to estimate that the oceanic plates are underlain by a layer 150 $\mathrm{km}$ thick with a viscosity of $1.5 \times 10^{19} \mathrm{~Pa}$ s. Hager [1991] suggested a model with a viscosity of $2 \times 10^{19} \mathrm{~Pa}$ s in a 300 $\mathrm{km}$ thick layer could explain a range of geophysical observations. Fjeldskaar [1994] used postglacial rebound in Fennoscandia to suggest that the asthenosphere has a thickness of less than $150 \mathrm{~km}$ and a viscosity of less than 7 $\times 10^{19} \mathrm{~Pa} \mathrm{~s}$.

[30] In the calculations presented above we have assumed a uniform viscosity for the asthenosphere. It has been suggested that the viscosity of the asthenosphere beneath the continents may be larger than beneath the oceans [e.g., Ricard et al., 1991]. If this is the case then our estimates for the properties of the asthenosphere should be taken as spatial averages. However, we do not expect that the possible errors introduced by our choice of a uniform viscosity will affect our conclusions.

[31] The final assumption we made regarding the asthenosphere was to neglect the influence of any local variations in the direction of mantle motion relative to the Indian plate. The very observation that we presented above, that the motion of the Indian plate can be explained in terms of the forces on the margins of the plate and basal drag parallel to the plate motion direction, lends support to this assumption. If the motion of the plate was governed by local and spatially variable mantle flow patterns, it would be unlikely that our calculated Euler poles would coincide with those observed.

\subsection{Diffuse Deformation in the NE Indian Ocean}

[32] Based on the observation that deformation at the boundaries of the Indian plate is much more significant than deformation within the plate, throughout this paper we have assumed that the plate behaves in an entirely rigid manner. However, some relatively slow and diffuse deformation is known to occur in the NE Indian Ocean [e.g., Gordon et al., 1998; Deplus et al., 1998; Delescluse and Chamot-Rooke, 2007; Krishna et al., 2009]. Merkouriev and DeMets [2006] suggest that this deformation is the result of the forces applied to the plate by the Tibetan Plateau. The formation of a clear throughgoing plate boundary in this region would have considerable implications for the tectonics of the Tibetan Plateau. If the forces from the ridges and subduction zones that surround Australia were no longer transmitted to the region of the Indian continent, then the Tibetan Plateau would form a much larger proportion of the boundary of the new Indian plate. The smaller forces exerted upon the other (now shortened) margins of the new plate are therefore no longer likely be large enough to maintain the northeastward motion of India. Given the large resistive force exerted upon the plate by the mountains on it's northern margin, the Tibetan Plateau may therefore undergo gravitational collapse, accommodated by reversed motion of the Indian plate.

\subsection{A More Global Perspective on Plate Driving Forces}

[33] Our study has shown that for the Indian plate basal traction resists, rather than drives, the motion of the plate. This finding is in contrast to Bird [1998], who suggested, based on a global model, that basal tractions may be a driving force. Given that our model only considers the rapidly moving Indian plate, and Bird's is a global model, this disagreement may suggest variations between the plates of the polarity of basal tractions.

[34] Our study additionally shows that the forces per unit length of plate boundary corresponding to "slab pull" along subduction zones and "ridge push" along oceanic ridges are of a similar magnitude for the Indian plate. One of the most persuasive arguments for the importance of subduction zone forces for driving the plates is the relation between absolute plate velocity and the proportion of a plate's margins that are subducting. Forsyth and Uyeda [1975] showed that the fast moving plates are subducting along a significant length of their boundaries (the Pacific, Indian, Cocos, Philippine, and Nazca plates). The slower moving plates (Eurasia, Antarctica, Africa, North and South America, and Arabia) are subducting along a relatively small proportion of their margins. It is obviously speculative to generalize from our conclusions regarding the forces exerted upon the Indian plate to the rest of the world. However, it is worth considering if our model for India, in which subduction zone forces are approximately equal in magnitude to midocean ridge forces, is compatible with observations from the 


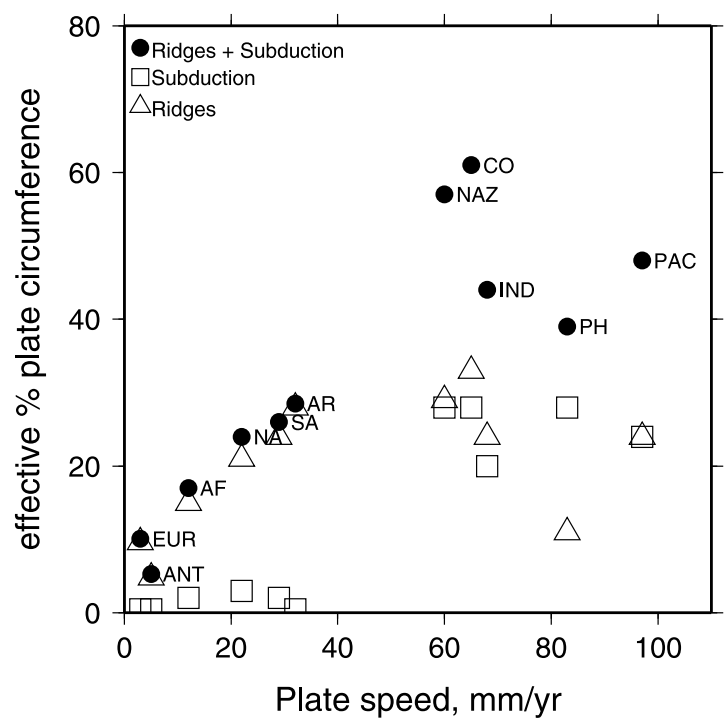

Figure 6. The relation between absolute plate velocity [Gripp and Gordon, 1990] and the effective proportion of a plate boundary where driving forces are applied [Cox and Hart, 1986]. Black circles represent a situation where ridges and subduction zones apply the same force to the plates. Open squares show the contribution from subduction zones, and open triangles show mid-ocean ridges. Plate abbreviations are EUR, Eurasia; ANT, Antarctica; AF, Africa; NA, North America; SA, South America; AR, Arabia; NAZ, Nazca; CO, Cocos; IND, India; PH, Philippine; PAC, Pacific. The open symbols are not labeled but are vertically beneath the black circle that corresponds to the same plate.

other plates. Figure 6 shows the relation between plate velocity and the effective proportion of the plate circumference where either subduction or spreading occurs (black circles). The effective length of a ridge/subduction zone is taken to be the length not balanced by an opposing ridge/ subduction zone, and so able to exert a net force upon the plate. We have taken our values for the effective plate boundary lengths from Cox and Hart [1986], and the absolute velocities of the plates from Gripp and Gordon [1990]. Also shown is the relation between velocity and the proportion of the plate boundary formed by subduction zones only (open squares) and mid-ocean ridges only (open triangles). If mid-ocean ridges are treated as being as important as subduction zones in driving plate motions (black circles), then the general relation between plate velocity and the proportion of the plate boundary providing driving forces still holds. In this case the distribution is more continuous, rather than the bimodal distribution observed if only the subduction zones are considered. The points do not lie on a straight line, and this would not be expected. Our simple treatment of the data only considers constant magnitude driving forces, and does not account for the possibility of variable magnitudes and distributions of resistive forces (such as those from mountain belts), which would be beyond the scope of this study. This simple first-order analysis demonstrates that the variability of absolute plate velocity is relatively well explained globally if the plates are assumed to be driven by forces along subduction zones and mid-ocean ridges that have similar magnitudes per unit length.

\section{Conclusions}

[35] We have performed force balance calculations for the Indian plate, for the times before and after the onset of mountain building in Tibet and the rearrangement of plate boundaries in the Indian Ocean. By comparing the torques resulting from forces on the margins of the plate and drag on the base of the plate we have been able to suggest that (1) subduction zones exert a similar force upon the Indian plate as the mid-ocean ridges, (2) the Tibetan Plateau resists the northward motion of India with a force of $5-6 \times 10^{12} \mathrm{~N} / \mathrm{m}$, and (3) the viscosity of the asthenosphere is $2-5 \times 10^{19} \mathrm{~Pa} \mathrm{~s}$, assuming a thickness of $100-$ $150 \mathrm{~km}$. We have shown that mountain building in Tibet was the major cause of the Cenozoic slowdown of the Indian plate. The reorganization of the plate boundaries in the Indian Ocean had a more minor effect, and may have actually been a consequence of the collision.

\section{Appendix A: Plate Reconstructions}

[36] Table A1 provides Royer and Patriat's [2002] rotation parameters for Capricorn-Somalia, and also our calculated rotation poles for India-Eurasia. These poles were used to derive the rates of motion of India relative to Asia shown in Figure 1. Ages given in Table A1 are from Cande and Kent's [1995] magnetic reversal timescale. Figure A1 shows a comparison between our estimate of India-Asia convergence, an estimate calculated using the reconstructions used by Molnar and Stock [2009], and also a third estimate which uses the Molnar and Stock [2009] plate circuit, but different reconstructions in the Atlantic Ocean. This third estimate uses the rotation parameters of Müller et al. [1999] and Gaina et al. [2002] for the central and north Atlantic, rather than those of McQuarrie et al. [2003] (which are based upon Klitgord and Schouten [1986], Srivastava and Tapscott [1986], and Srivastava et al. [1990]).

\section{Appendix B: Potential Energy Contrasts in New Guinea and Southern New Zealand}

[37] In this appendix we calculate the potential energy differences between the mountains and lowlands in New Guinea and southern New Zealand, in order to estimate the forces applied to the margins of the Indian plate in these regions. The difference in gravitational potential energy between two isostatically compensated lithospheric columns of unit area is equivalent to the vertical integral of the difference in vertical normal stress between the two areas, i.e., $\triangle G P E=\int \Delta \sigma_{z z} d z$, where the integral is between the surface of the mountains and the depth of isostatic compensation, $\sigma_{z z}$ is the vertical normal stress $\left(\partial \sigma_{z z} / \partial z=\rho g\right)$, and $\Delta \sigma_{z z}$ refers to the difference in $\sigma_{z z}$ at a given depth between the two lithospheric columns being considered [e.g., Molnar and Lyon-Caen, 1988].

[38] The mountains of New Guinea rise to altitudes of $\sim 3.5 \mathrm{~km}$ in the long-wavelength topography. The crustal thickness in the region is not well known, so we have 


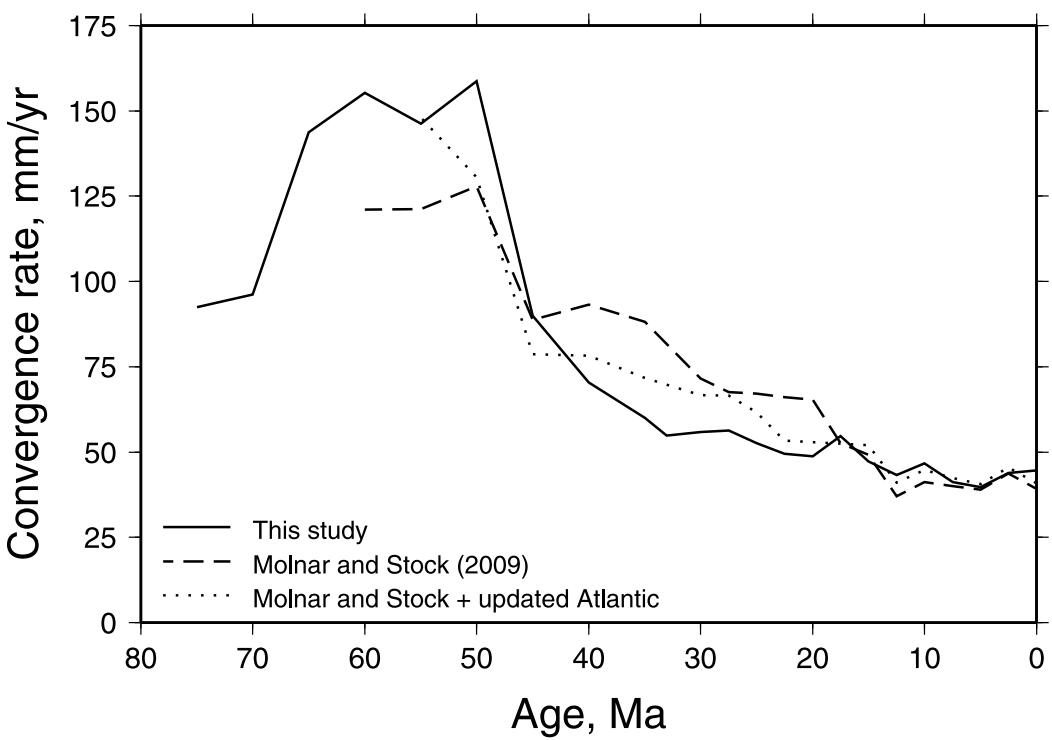

Figure A1. A comparison between our estimate of the India-Asia convergence (solid line), an estimate calculated using the plate circuit used by Molnar and Stock [2009] (dashed line), and an estimate using the Molnar and Stock [2009] circuit but different reconstructions in the Atlantic Ocean, as described in the text (dotted line). The difference between the dashed and dotted lines represents the effect of using alternative reconstructions in the Atlantic. Differences between the solid and dotted lines shows the effect of Indian Ocean rotation poles. Velocities are calculated at $5 \mathrm{Myr}$ increments before $30 \mathrm{Myr}$ and then at 2.5 Myr increments to the present-day.

Table A1. Rotation Parameters for Capricorn-Somalia and Calculated Rotation Poles for India-Eurasia

\begin{tabular}{|c|c|c|c|c|}
\hline Chron & Age (Ma) & Latitude & Longitude & Angle (deg) \\
\hline \multicolumn{5}{|c|}{ Capricorn Relative to Somalia } \\
\hline 80 & 26.55 & 14.80 & 46.00 & -15.400 \\
\hline 130 & 33.06 & 18.70 & 46.10 & -17.770 \\
\hline 180 & 40.13 & 16.60 & 48.80 & -22.310 \\
\hline $20 \mathrm{o}$ & 43.79 & 17.00 & 48.10 & -24.090 \\
\hline 210 & 47.91 & 12.60 & 48.30 & -28.340 \\
\hline 220 & 49.71 & 14.60 & 44.00 & -27.720 \\
\hline 230 & 51.74 & 14.90 & 41.90 & -29.930 \\
\hline 240 & 53.35 & 15.90 & 38.60 & -31.110 \\
\hline 250 & 55.90 & 17.60 & 33.90 & -32.700 \\
\hline 260 & 57.91 & 17.60 & 31.90 & -34.630 \\
\hline $27 \mathrm{y}$ & 60.92 & 14.00 & 33.40 & -40.220 \\
\hline 280 & 62.50 & 15.30 & 31.00 & -40.500 \\
\hline $29 \mathrm{o}$ & 64.75 & 14.10 & 30.20 & -44.710 \\
\hline $31 y$ & 67.74 & 15.70 & 24.90 & -45.880 \\
\hline 320 & 73.00 & 17.70 & 21.70 & -49.140 \\
\hline $34 y$ & 83.00 & 16.80 & 21.20 & -55.000 \\
\hline \multicolumn{5}{|c|}{ India Relative to Eurasia } \\
\hline & 5.0 & 26.61 & 23.39 & -2.60 \\
\hline & 10.0 & 25.41 & 20.11 & -4.70 \\
\hline & 15.0 & 23.81 & 21.06 & -7.26 \\
\hline & 20.0 & 24.29 & 20.88 & -10.11 \\
\hline & 25.0 & 21.36 & 27.95 & -13.76 \\
\hline & 30.0 & 23.39 & 27.74 & -16.97 \\
\hline & 35.0 & 24.43 & 27.68 & -20.22 \\
\hline & 40.0 & 22.92 & 29.37 & -24.37 \\
\hline & 45.0 & 21.74 & 28.84 & -28.45 \\
\hline & 50.0 & 20.35 & 25.68 & -32.39 \\
\hline & 55.0 & 21.67 & 19.67 & -38.73 \\
\hline & 60.0 & -19.89 & -161.39 & 46.09 \\
\hline & 65.0 & -18.79 & -163.25 & 53.39 \\
\hline & 70.0 & -20.47 & -168.60 & 57.93 \\
\hline & 75.0 & -21.06 & -169.94 & 62.07 \\
\hline & 80.0 & 20.79 & 9.56 & -66.46 \\
\hline
\end{tabular}

${ }^{\mathrm{a}}$ From Royer and Patriat [2002]. assumed values of $30 \mathrm{~km}$ beneath the lowlands and $55 \mathrm{~km}$ beneath the mountains (a likely value for an isostatically compensated $3.5 \mathrm{~km}$ high mountain range). The resulting potential energy contrast between the mountains and the lowlands in this situation is $\sim 4 \times 10^{12} \mathrm{~N}$ per unit length along strike.

[39] The mountains of the south island of New Zealand rise to $\sim 2 \mathrm{~km}$ in the long-wavelength topography. The crustal thickness is a maximum of $\sim 45 \mathrm{~km}$ beneath the highest mountains, and is $\sim 25 \mathrm{~km}$ beneath the lowlands [Scherwath et al., 2003]. The potential energy difference between the mountains and the lowlands is therefore $\sim 2 \times$ $10^{12} \mathrm{~N}$ per unit length along strike.

[40] Acknowledgments. We thank the Gordon and Betty Moore Foundation for financial support. This is Caltech Tectonics Observatory contribution 121. C. DeMets and one anonymous reviewer provided useful comments on the manuscript. The figures were produced using the Generic Mapping Tools (GMT) [Wessel and Smith, 1995].

\section{References}

Aikman, A. B., T. M. Harrison, and D. Lin (2008), Evidence for early (>44 Ma Himalayan crustal thickening, Tethyan Himalaya, southeastern Tibet, Earth Planet. Sci. Lett., 274, 14-23, doi:10.1016/j.eps1.2008. 06.038

Artyushkov, E. V. (1973), Stresses in the lithosphere caused by crustal thickness inhomogeneities, J. Geophys. Res., 78, 7675-7708, doi:10.1029/JB078i032p07675.

Bernard, A., M. Munschy, Y. Rotstein, and D. Sauter (2005), Refined spreading history of the Southwest Indian Ridge for the last $96 \mathrm{Ma}$, with the aid of satellite gravity data, Geophys. J. Int., 162, 765-778, doi:10.1111/j.1365-246X.2005.02672.x.

Billen, M. I., and M. Gurnis (2001), A low viscosity wedge in subduction zones, Earth Planet. Sci. Lett., 193, 227-236, doi:10.1016/S0012821X(01)00482-4.

Bird, P. (1998), Testing hypotheses on plate-driving mechanisms with global lithosphere models including tomography, thermal structure, and faults, J. Geophys. Res., 103, 10,115-10,129, doi:10.1029/98JB00198. 
Bird, P. (2003), An updated digital model of plate boundaries, Geochem. Geophys. Geosyst., 4(3), 1027, doi:10.1029/2001GC000252.

Cande, S. C., and D. V. Kent (1995), Revised calibration of the geomagnetic polarity timescale for the late cretaceous and cenozoic, $J$. Geophys. Res., 100, 6093-6095, doi:10.1029/94JB03098.

Cande, S. C., and J. C. Mutter (1982), A revised identification of the oldest sea-floor spreading anomalies between Australia and Antarctica, Earth Planet. Sci. Lett., 58, 151-160, doi:10.1016/0012-821X(82)90190-X.

Cande, S. C., C. A. Raymond, J. Stock, and W. F. Haxby (1995), Geophysics of the Pitman Fracture Zone and Pacific-Antarctic plate motions during the Cenozoic, Science, 270, 947-953, doi:10.1126/science. 270.5238 .947

Cande, S. C., J. M. Stock, R. D. Mueller, and T. Ishihara (2000), Cenozoic motion between east and west Antarctica, Nature, 404, 145-150, doi:10.1038/35004501.

Coblentz, D. D., M. Sandiford, R. M. Richardson, S. Zhou, and R. Hillis (1995), The origins of the intraplate stress field in continental Australia Earth Planet. Sci. Lett., 133, 299-309, doi:10.1016/0012-821X(95) 00084-P.

Coblentz, D. D., S. Zhou, R. R. Hillis, R. M. Richardson, and M. Sandiford (1998), Topography, boundary forces, and the Indo-Australian intraplate stress field, J. Geophys. Res., 103, 919-931, doi:10.1029/97JB02381.

Conrad, C. P., and B. H. Hager (1999), Effects of plate bending and faul strength at subduction zones on plate dynamics, J. Geophys. Res., 104, 17,551-17,571, doi:10.1029/1999JB900149.

Cox, A., and R. B. Hart (1986), Plate Tectonics: How It Works, Blackwell Sci., Palo Alto, Calif.

Craig, C. H., and D. McKenzie (1986), The existence of a thin lowviscosity layer beneath the lithosphere, Earth Planet. Sci. Lett., 78 , 420-426, doi:10.1016/0012-821X(86)90008-7.

Debayle, E., B. Kennett, and K. Priestley (2005), Global azimuthal seismic anisotropy and the unique plate-motion deformation of Australia, Nature, 433, 509-512, doi:10.1038/nature03247.

Delescluse, M., and N. Chamot-Rooke (2007), Instantaneous deformation and kinematics of the India-Australia Plate, Geophys. J. Int., 168, 818 842, doi:10.1111/j.1365-246X.2006.03181.x.

DeMets, C., R. G. Gordon, and J.-Y. Royer (2005), Motion between the Indian, Capricorn and Somalian plates since $20 \mathrm{Ma}$ : Implications for the timing and magnitude of distributed lithospheric deformation in the equatorial Indian Ocean, Geophys. J. Int., 161, 445-468, doi:10.1111/j.1365-246X.2005.02598.x.

Deplus, C., M. Diament, H. Herbert, G. Bertrand, S. Dominguez, J. Dubois, J. Malod, P. Patriat, B. Pontoise, and J.-J. Sibilla (1998), Direct evidence of active deformation in the eastern Indian oceanic plate, Geology, 26 131-134, doi:10.1130/0091-7613(1998)026<0131:DEOADI >2.3.CO;2.

de Sigoyer, J., V. Chavagnac, J. Blichert-Toft, I. M. Villa, B. Luais, S. Guillot, M. Cosca, and G. Mascle (2000), Dating the Indian continental subduction and collisional thickening in the northwest Himalaya: Multichronology of the Tso Morari eclogites, Geology, 28, 487-490, doi:10.1130/0091-7613(2000)28<487:DTICSA $>2.0 . C O ; 2$.

Emmerson, B., and D. McKenzie (2007), Thermal structure and seismicity of subducting lithosphere, Phys. Earth Planet. Inter., 163, 191-208, doi:10.1016/j.pepi.2007.05.007.

Engdahl, E. R., R. van der Hilst, and R. Buland (1998), Global teleseismic earthquake relocation with improved travel times and procedures for depth determination, Bull. Seismol. Soc. Am., 88, $722-743$.

Fjeldskaar, W. (1994), Viscosity of the asthenosphere detected from the fennoscandian uplift, Earth Planet. Sci. Lett., 126, 399-410, doi:10.1016/0012-821X(94)90120-1.

Fluteau, F., G. Ramstein, and J. Besse (1999), Simulating the evolution of the Asian and African monsoons during the past 30 Myr using an atmospheric general circulation model, J. Geophys. Res., 104, 11,995-12,018, doi:10.1029/1999JD900048.

Forsyth, D., and S. Uyeda (1975), On the relative importance of the driving forces of plate motion, Geophys. J. R. Astron. Soc., 43, 163-200.

Gaina, C., W. R. Roest, and R. D. Müller (2002), Late Cretaceous-Cenozoic deformation of northeast Asia, Earth Planet. Sci. Lett., 197, 273-286, doi:10.1016/S0012-821X(02)00499-5.

Gordon, R. G., C. DeMets, and J.-Y. Royer (1998), Evidence for long-term diffuse deformation of the lithosphere of the equatorial Indian Ocean, Nature, 395, 370-374, doi:10.1038/26463.

Gripp, A. E., and R. G. Gordon (1990), Current plate velocities relative to the hotspots incorporating the NUVEL-1 global plate motion model, Geophys. Res. Lett., 17, 1109-1112, doi:10.1029/GL017i008p01109.

Guillot, S., E. Garzanti, D. Baratoux, D. Marquer, G. Mahéo, and J. de Sigoyer (2003), Reconstructing the total shortening history of the NW Himalaya, Geochem. Geophys. Geosyst., 4(7), 1064, doi:10.1029/ $2002 \mathrm{GC} 000484$

Hager, B. H. (1991), Mantle viscosity: A comparison of models from postglacial rebound and from the geoid, plate driving forces, and advected heat flux, in Glacial Isostasy, Sea-Level and Mantle Rheology, edited by R. Sabadini, K. Lambeck, and E. Boschi, pp. 493-513, Kluwer Acad., Dordrecht, Netherlands.

Hirth, G., and D. L. Kohlstedt (2003), Rheology of the upper mantle and the mantle wedge: A view from the experimentalists, in Inside the Subduction Factory, Geophys. Monogr. Ser., vol. 138, edited by J. Eiler, pp. 83-105, AGU, Washington, D. C

Karato, S.-I., and P. Wu (1993), Rheology of the upper mantle: A synthesis, Science, 260, 771-778, doi:10.1126/science.260.5109.771

Klitgord, K. D., and H. Schouten (1986), Plate kinematics of the central Atlantic, in The Geology of North America, vol. M, The Western North Atlantic Region, edited by P. R. Vogt and B. E. Tucholke, pp. 351-378, Geol. Soc. of Am., Boulder, Colo.

Krishna, K. S., J. M. Bull, and R. A. Scrutton (2009), Early (pre-8 Ma) fault activity and temporal strain accumulation in the central Indian Ocean, Geology, 37, 227-230, doi:10.1130/G25265A.1.

Lamb, S. (2006), Shear stresses on megathrusts: Implications for mountain building behind subduction zones, J. Geophys. Res., 111, B07401, doi:10.1029/2005JB003916.

Lemaux, J., R. G. Gordon, and J.-Y. Royer (2002), Location of the NubiaSomalia boundary along the Southwest Indian Ridge, Geology, 30, 339342, doi:10.1130/0091-7613(2002)030<0339:LOTNSB >2.0.CO;2.

Leveque, J. J., E. Debayle, and V. Maupin (1998), Anisotropy in the Indian Ocean upper mantle from Rayleigh- and Love-waveform inversion, Geophys. J. Int., 133, 529-540, doi:10.1046/j.1365-246X.1998.00504.x.

Lithgow-Bertelloni, C., and M. A. Richards (1995), Cenozoic plate driving forces, Geophys. Res. Lett., 22, 1317-1320, doi:10.1029/95GL01325.

Liu, C.-S., J. R. Curray, and J. M. McDonald (1983), New constraints on the tectonic evolution of the eastern Indian Ocean, Earth Planet. Sci. Lett., 65, 331-342, doi:10.1016/0012-821X(83)90171-1.

McQuarrie, N., J. M. Stock, C. Verdel, and B. P. Wernicke (2003), Cenozoic evolution of Neotethys and implications for the causes of plate motions, Geophys. Res. Lett., 30(20), 2036, doi:10.1029/2003GL017992.

Merkouriev, S., and C. DeMets (2006), Constraints on Indian plate motion since $20 \mathrm{Ma}$ from dense Russian magnetic data: Implications for Indian plate dynamics, Geochem. Geophys. Geosyst., 7, Q02002, doi:10.1029/ 2005GC001079.

Merkouriev, S., and C. DeMets (2008), A high-resolution model for Eurasia-North America plate kinematics since $20 \mathrm{Ma}$, Geophys. J. Int., 173 1064-1083, doi:10.1111/j.1365-246X.2008.03761.x.

Molnar, P., and H. Lyon-Caen (1988), Some simple physical aspects of the support, structure, and evolution of mountain belts, in Processes in Continental Lithospheric Deformation, edited by S. P. Clark Jr., Spec. Pap. Geol. Soc. Am., 218, 179-207.

Molnar, P., and J. M. Stock (2009), Slowing of India's convergence with Eurasia since $20 \mathrm{Ma}$ and its implications for Tibetan mantle dynamics, Tectonics, 28, TC3001, doi:10.1029/2008TC002271.

Molnar, P., and P. Tapponnier (1975), Cenozoic tectonics of Asia: Effects of a continental collision, Science, 189, 419-426, doi:10.1126/science. 189.4201.419.

Molnar, P., F. Pardo-Casas, and J. Stock (1988), The Cenozoic and late Cretaceous evolution of the Indian Ocean basin: Uncertainties in the reconstructed positions of the Indian, African, and Antarctic plates, Basin Res., 1, 23-40, doi:10.1111/j.1365-2117.1988.tb00003.x.

Molnar, P., P. England, and J. Martinod (1993), Mantle dynamics, uplift of the Tibetan Plateau, and the Indian monsoon, Rev. Geophys., 31, $357-$ 396, doi:10.1029/93RG02030.

Morgan, J. P., and E. M. Parmentier (1984), Lithospheric stress near ridge-transform intersection, Geophys. Res. Lett., 11, 113-116, doi:10.1029/GL011i002p00113.

Mount, V. S., and J. Suppe (1992), Present-day stress orientations adjacent to active strike-slip faults, California and Sumatra, J. Geophys. Res., 97, 11,995-12,013, doi:10.1029/92JB00130.

Müller, R. D., W. R. Roest, J.-Y. Royer, L. M. Gahagan, and J. G. Scalter (1997), Digital isochrons of the world oceans, J. Geophys. Res., 102 3211-3214, doi:10.1029/96JB01781.

Müller, R. D., J.-Y. Royer, S. C. Cande, W. R. Roest, and S. Maschenkov (1999), New constraints on the Late Cretaceous/Tertiary plate tectonic evolution of the Caribbean, in Sedimentary Basins of the World, vol. 4 , Caribbean Basin, pp. 33-59, Elsevier Sci., Amsterdam.

Müller, R. D., M. Sdrolias, C. Gaina, and W. R. Roest (2008a), Age, spreading rates, and spreading asymmetry of the world's ocean crust, Geochem. Geophys. Geosyst., 9, Q04006, doi:10.1029/2007GC001743.

Müller, R. D., M. Sdrolias, C. Gaina, B. Steinberger, and C. Heine (2008b), Long-term sea-level fluctuations driven by ocean basin dynamics, Science, 319, 1357-1362, doi:10.1126/science.1151540.

Parsons, B., and F. M. Richter (1980), A relation between the driving force and geoid anomaly associated with mid-ocean ridges, Earth Planet. Sci. Lett., 51, 445-450, doi:10.1016/0012-821X(80)90223-X. 
Patriat, P., and J. Achache (1984), India-eurasia collision chronology has implications for crustal shortening and driving mechanism of plates, Nature, 311, 615-621, doi:10.1038/311615a0.

Ramstein, G., F. Fluteau, J. Besse, and S. Joussaume (1997), Effect of orogeny, plate motion and land-sea distribution on Eurasian climate change over the past 30 million years, Nature, 386, 788-795, doi:10.1038/386788a0.

Reynolds, S. D., D. D. Coblentz, and R. R. Hillis (2002), Tectonic forces controlling the regional intraplate stress field in continental Australia: Results from new finite element modeling, J. Geophys. Res., 107(B7), 2131, doi:10.1029/2001JB000408.

Ricard, Y., C. Doglioni, and R. Sabadini (1991), Differential rotation between lithosphere and mantle: A consequence of lateral mantle viscosity variations, J. Geophys. Res., 96, 8407-8415, doi:10.1029/91JB00204.

Richardson, R. M. (1992), Ridge forces, absolute plate motions, and the intraplate stress field, J. Geophys. Res., 97, 11,739-11,748, doi:10.1029/ 91JB00475.

Robinson, E. M., and B. Parsons (1988), Effect of a shallow low-viscosity zone on small-scale instabilites under the cooling oceanic plates, J. Geophys. Res., 93, 3469-3479, doi:10.1029/JB093iB04p03469.

Rowley, D. B. (1996), Age of initiation of collision between India and Asia: A review of stratigraphic data, Earth Planet. Sci. Lett., 145, 1-13, doi:10.1016/S0012-821X(96)00201-4.

Rowley, D. B., and B. S. Currie (2006), Palaeo-altimetry of the late Eocene to Miocene Lunpola basin, central Tibet, Nature, 439, 677-681, doi:10.1038/nature04506.

Royer, J.-Y., and T. Chang (1991), Evidence for relative motions between the Indian and Australian plates during the last 20 m.y. from plate tectonic reconstructions: Implications for the deformation of the IndoAustralian plate, J. Geophys. Res., 96, 11,779-11,802, doi:10.1029/ 91JB00897.
Royer, J. Y., and P. Patriat (2002), L'inde part a la derive, in HimalayaTibet, Le Choc des Continents, edited by C. J. Allegre, J.-P. Avouac, and P. De Wever, pp. 25-31, Mus. Natl. de'Hist. Nat., Paris.

Sandiford, M., D. D. Coblentz, and R. M. Richardson (1995), Ridge torques and continental collision in the Indo-Australian plate, Geology, 23, 653 656, doi:10.1130/0091-7613(1995)023<0653:RTACCI $>2.3$. CO;2.

Scherwath, M., T. Stern, F. Davey, D. Okaya, W. S. Holbrook, R. Davies, and S. Kleffmann (2003), Lithospheric structure across oblique continental collision in New Zealand from wide-angle $P$ wave modeling, $J$. Geophys. Res., 108(B12), 2566, doi:10.1029/2002JB002286.

Srivastava, S. P., and C. R. Tapscott (1986), Plate kinematics of the North Atlantic, in The Geology of North America, vol. M, The Western North Atlantic Region, edited by P. R. Vogt and B. E. Tucholke, pp. 379-404, Geol. Soc. of Am., Boulder, Colo.

Srivastava, S. P., W. R. Roest, L. C. Kovacs, G. Oakey, S. Levesque, J. Verhoef, and R. Macnab (1990), Motion of Iberia since the Late Jurassic; results from detailed aeromagnetic measurements in the Newfoundland Basin, Tectonophysics, 184, 229-260, doi:10.1016/00401951(90)90442-B.

Wessel, P., and W. H. F. Smith (1995), New version of the Generic Mapping Tools released, Eos Trans. $A G U, 76,329$, doi:10.1029/95EO00198.

Wessel, P., Y. Harada, and L. W. Kroenke (2006), Toward a self-consistent, high-resolution absolute plate motion model for the Pacific, Geochem. Geophys. Geosyst., 7, Q03L12, doi:10.1029/2005GC001000.

J.-P. Avouac and A. Copley, Tectonics Observatory, Division of Geological and Planetary Sciences, California Institute of Technology, Pasadena, CA 91125, USA. (avouac@gps.caltech.edu; copley@gps.caltech. edu)

J.-Y. Royer, Domaines Oceaniques, IUEM, UBO, CNRS, Place Nicolas Copernic, F-29280 Plouzane, France. (jyroyer@univ-brest.fr) 